Western University

Scholarship@Western

Civil and Environmental Engineering

Civil and Environmental Engineering

Publications

Department

2017

Ductile Corrosion-Free GFRP-Stainless Steel Reinforced Concrete Elements

Maged A. Youssef

Western University, youssef@uwo.ca

Mohamed E. Meshaly

Alexandria University

Ahmed Elansary

The University of Western Ontario

Follow this and additional works at: https://ir.lib.uwo.ca/civilpub

Part of the Structural Engineering Commons

Citation of this paper:

Youssef, Maged A.; Meshaly, Mohamed E.; and Elansary, Ahmed, "Ductile Corrosion-Free GFRP-Stainless Steel Reinforced Concrete Elements" (2017). Civil and Environmental Engineering Publications. 195.

https://ir.lib.uwo.ca/civilpub/195 


\title{
Ductile Corrosion-Free GFRP-Stainless Steel Reinforced Concrete Elements
}

\author{
Maged A. Youssef ${ }^{1, *}$, Mohamed E. Meshaly ${ }^{1,2}$, Ahmed A. Elansary ${ }^{1,3}$ \\ ${ }^{1}$ Civil and Environmental Engineering, Western University, London, Ontario, Canada, N6A 5B9 \\ ${ }^{2}$ Department of Structural Engineering, Alexandria University, Alexandria, Egypt \\ ${ }^{3}$ Department of Structural Engineering, Cairo University, Giza, Egypt
}

\begin{abstract}
Corrosion of steel rebars is known to cause deterioration of concrete structures that can lead to catastrophic failures. To mitigate this problem, steel rebars can be replaced with Glass FiberReinforced Polymer (GFRP) rebars. However, the lack of ductility of GFRP-reinforced elements has prevented their use in many structural applications, especially in seismic areas. Stainless Steel (SS) rebars are corrosion resistant and have adequate energy absorption and ductility. However, they are much more expensive than steel rebars. This paper proposes the combined use of SS and GFRP rebars to achieve ductile and corrosion-free elements. The first challenge for such a proposal relates to designing SS-GFRP reinforced concrete frame with adequate lateral performance in terms of initial stiffness, ductility, and strength. Design equations, which are based on a comprehensive parametric study, are developed to allow designing such a frame. A six-storey concrete frame is then designed using the proposed equations and its lateral performance is examined using pushover analysis.
\end{abstract}

Keywords: Concrete, Beams, Columns, Frames, GFRP, SS, Pushover.

${ }^{*}$ Corresponding author. Tel.: 519-661-2111 ext. 88661.

E-mail address: youssef@uwo.ca (Maged A. Youssef) 


\section{Introduction}

The use of Fiber-Reinforced Polymer (FRP) rebars as a replacement for steel rebars has emerged as an innovative solution to overcome the corrosion problem. Moreover, FRP rebars have the advantages of: (1) high resistance to electrical and magnetic fields, (2) high strength, (3) lightweight, and (4) availability [1, 2, 3]. Due to their inability to dissipate seismic energy, the use of FRP rebars in concrete structures is limited [4]. FRP reinforced concrete (RC) structures have significantly less ductility and energy dissipation capacity than steel RC structures.

The behaviour of FRP RC elements was examined by many researchers $[5,6,7,8,9,10,11,12$, $13,14,15,16,17,18,19]$. An experimental program for concrete columns reinforced with longitudinal and transverse GFRP rebars was conducted by Tobbi et al. [20, 21, 22]. Their study revealed that GFRP RC columns withstood loads similar to or higher than steel RC columns. The experimental results were then used to develop a strength model for square columns reinforced with longitudinal and transverse GFRP reinforcement. Experimental programs on circular concrete columns reinforced with GFRP hoops and spirals were performed by Pantelides et al. [23], Mohamed et al. [24], and Afifi et al. [25]. The behaviour of GFRP-confined concrete cores were found to be similar to that of steel-confined concrete cores. Based on the experimental results, Afifi et al. [26] developed a mechanical model for circular concrete columns reinforced with GFRP spirals or hoops. The model accounted for the transverse reinforcement volumetric ratio, strength, spacing, and configuration. Another experimental study on circular and square concrete columns with longitudinal and transverse GFRP hoops/spirals was carried out by Prachasaree et al. [19]. They concluded that spiral transverse reinforcement is the most effective in terms of confining pressure and ductility. 
Another material that received the interest of the research community is Stainless Steel (SS). Its heat and corrosion resistance, ability to withstand impact and shock, and little cost of maintenance make it a perfect replacement for steel rebars in concrete structures $[27,28,29,30]$. However, the high cost of SS and the lack of design guidelines/standards have limited such a replacement. Billah and Alam [17] investigated analytically the seismic behavior of hybrid RC columns with SS at the plastic hinge zone and FRP at the other regions, and compared their performance to that of a SS reinforced columns in terms of base shear-displacement, base shear demand/capacity ratio, ductility, residual displacement, and energy dissipation capacity. In their investigation, a pushover analysis was conducted for the SS and FRP-SS reinforced columns. Also, the same columns were analyzed under 20 natural ground motions. The analytical results showed that the SS RC column experienced higher ductility as compared to the FRP-SS RC column. It is worth mentioning that Billah and Alam [17] utilized the same steel and concrete areas in both the FRP-SSRC column and the SS RC column. The low modulus of elasticity for FRP led to much lower stiffness, strength and ductility for the FRP-SSRC column.

In the present study, the authors adopted the concept of a hybrid reinforcement configuration (GFRP and SS) to achieve an improved ductility and high corrosion resistance at a reasonable cost. The SS rebars are assumed to reinforce the plastic hinge regions of typical RC frames. The FRP and SS rebars are assumed to be connected using suitable couplers as suggested by Alam et al. [31]. The objectives of this study are: (1) to assess the performance of concrete elements reinforced with SS rebars at the plastic hinge regions and GFRP rebars at the other regions, and (2) to develop design criteria to ensure that the GFRP-SS frame lateral performance is acceptable in terms of stiffness, strength, and ductility. The following sections provide details about the modeling 
assumptions, lateral performance of GFRP-SS RC frames, parametric study to achieve design procedure for FRP-SS RC frames, and a case study to examine the developed design procedure.

\section{Modeling Assumptions}

\subsection{Material Constitutive Models}

The concrete is modeled using a uniaxial nonlinear constant confinement concrete model that follows the constitutive relationship proposed by Mander et al. [32] and the cyclic rules proposed by Martinez-Rueda and Elnashai [33]. Two different concrete compressive strengths $\left(f_{c}^{\prime}\right)$ are considered (30 MPa and $40 \mathrm{MPa}$ ). The yield strength, modulus of elasticity, and strain hardening parameters for the steel rebars are assumed to be $400 \mathrm{MPa}, 200,000 \mathrm{MPa}$, and 0.02 , respectively.

The properties of the transverse GFRP reinforcement, summarized in Table 1, were assumed based on the values reported Tobbi et al. [21]. Where $E_{f}$ is the modulus of elasticity, $f_{f t u}$ is the ultimate tensile strength, and $\varepsilon_{f u}$ is the ultimate tensile strain. The properties of the longitudinal GFRP rebars depend on the rebar size and its modulus of elasticity. The assumed values are summarized in Table 2 .

The stress-strain curve of SS is assumed to be bilinear as shown in Fig. 1. The yield strength, modulus of elasticity, and strain hardening parameters for the SS rebars are assumed to be 400 $\mathrm{MPa}, 190,000 \mathrm{MPa}$, and 0.025 , respectively.

Table 1 Transverse GFRP reinforcement properties recommended by Tobbi et al. [21]

\begin{tabular}{lccc} 
& $E_{f}(\mathrm{MPa})$ & $f_{f t u}(\mathrm{MPa})$ & $\varepsilon_{f u}(\%)$ \\
\cline { 1 - 1 } Straight portion & 44,000 & 640 & 1.45 \\
\cline { 1 - 1 } Bent portion & & 400 & \\
\cline { 1 - 2 } & & &
\end{tabular}


Table 2 Longitudinal GFRP reinforcement properties

\begin{tabular}{|c|c|c|c|c|}
\hline \multirow{2}{*}{$\begin{array}{c}\text { Bar Diameter } \\
(\mathrm{mm})\end{array}$} & \multicolumn{2}{|c|}{$\mathrm{E}_{f}=46,000 \mathrm{MPa}$} & \multicolumn{2}{c|}{$\mathrm{E}_{f}=65,000 \mathrm{MPa}$} \\
\cline { 2 - 5 } & $f_{f t u}(\mathrm{MPa})$ & $\varepsilon_{f u}(\%)$ & $f_{f t u}(\mathrm{MPa})$ & $\varepsilon_{f u}(\%)$ \\
\hline 10 & 827 & 1.80 & 1372 & 2.11 \\
\hline 13 & 758 & 1.65 & 1312 & 2.02 \\
\hline 16 & 724 & 1.57 & 1184 & 1.82 \\
\hline 19 & 690 & 1.50 & 1105 & 1.70 \\
\hline 22 & 655 & 1.42 & 1059 & 1.63 \\
\hline 25 & 620 & 1.35 & 1000 & 1.54 \\
\hline
\end{tabular}

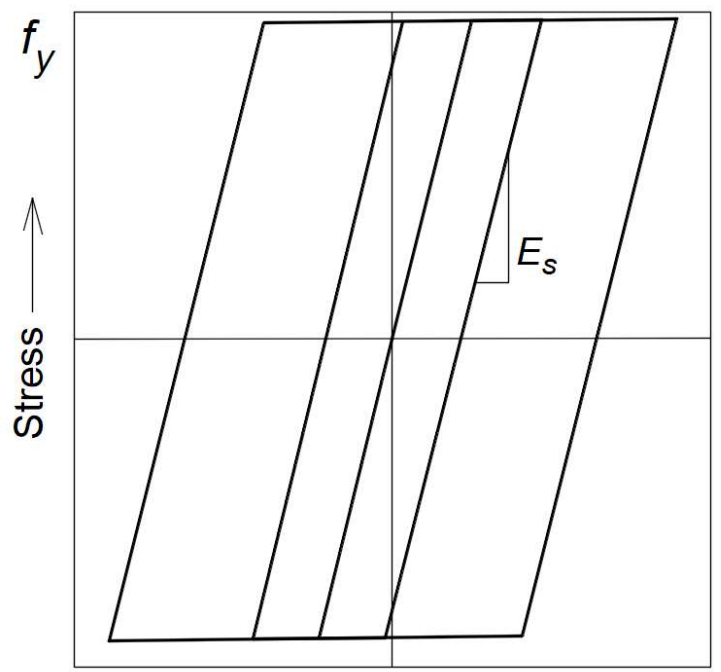

Strain $\longrightarrow$

Fig. 1 Stress-strain curve of SS under cyclic load. 


\subsection{Modeling}

Beams and columns are individually modeled as cantilevers with length of $(0.5 \mathrm{~L})$ or $(0.5 \mathrm{H})$, where $\mathrm{L}$ is the beam span and $\mathrm{H}$ is the column height. A lateral load, $\mathrm{P}_{\mathrm{L}}$, is assumed to be acting at the cantilever's tip. The value of the axial load is assumed zero for the beams and $\mathrm{P}_{\mathrm{A}}$ for the columns. Ten displacement-based frame elements in the SeismoStruct model [34] are used to model each of the beams and columns. The spread of inelasticity along the member length is captured using 200 fibers. The section stress-strain state is obtained through the integration of the nonlinear uniaxial stress-strain response of the individual fibers forming the cross section.

When modeling a complete RC frame, the same elements are utilized. Additionally, the beams are modeled as T-sections to account for the floor slab. The beam-column joints are assumed to be rigid. Dead loads are then applied before applying the lateral loads.

\subsection{Failure Criteria}

The ultimate strain of the unconfined concrete in the beams $\left(\varepsilon_{u \text { (unconfined })}^{S}\right)$ is assumed equal to 0.004. For confined steel RC columns, the core concrete ultimate strain $\left(\varepsilon_{u(\text { confined })}^{S}\right)$ is calculated using Eq. (1) by Paulay and Priestley [35].

$$
\varepsilon_{u(\text { confined })}^{s}=\varepsilon_{u(\text { unconfined })}^{s}+\frac{1.4 \rho_{s} f_{y} \varepsilon_{s m}}{k_{h}^{s} f_{c}^{\prime}}
$$

where $\rho_{s}$ is the ratio of the volume of transverse reinforcement of concrete core measured to the outside of the transverse reinforcement, $\varepsilon_{s m}$ is the steel strain at maximum tensile stress, $k_{h}^{s}$ is the confinement factor, which can be obtained from the charts provided by Priestley and Wood [36].

The ultimate strain for columns confined with GFRP lateral stirrups $\left(\varepsilon_{u}^{f}\right)$ is calculated using Eq. (2) by Afifi et al. [26]. 


$$
\varepsilon_{u}^{f}=\left[0.000937\left(f_{c o}^{\prime}\right)^{0.25}\right] \cdot\left[0.63+\left(70.6-1.76 f_{c o}^{\prime}\right) \sqrt{\frac{f_{l e}}{f_{c o}^{\prime}}}\right]
$$

where $f_{c o}^{\prime}$ is the strength of unconfined concrete and $f_{l e}$ is the effective lateral pressure. $k_{h}^{f}$ is the confinement factor for GFRP stirrups, which can be obtained using Eq. (3) by Tobbi et al. [22].

$$
k_{h}^{f}=1+1.23\left(\frac{f_{l e}}{f_{c o}^{\prime}}\right)^{0.71}
$$

Both the beam and column elements are assumed to fail when the concrete reaches the ultimate strain. Frames are assumed to fail when the ultimate strain of concrete or the ultimate strain of steel is reached in all columns of the same storey.

The shear in the GFRP-SS RC elements is checked using the equations provided in ACI 318-14 [37] standard as recommended by Bentz et al. [38].

\section{Lateral Performance of GFRP-SS RC Frames}

A six-storey steel RC frame (Frame 1) designed by Youssef and Elfeki [39] and shown in Fig. 2 is considered in this section. The yield strength of the steel rebars is $400 \mathrm{MPa}$ and the concrete compressive strength is $28 \mathrm{MPa}$. Cross sections of the beams and columns are presented in Fig. 3.

Frame 2 is a revised design of Frame 1, which utilizes SS and GFRP instead of the steel rebars. The areas of the concrete and the rebars are kept unchanged. Steel rebars are replaced with equal areas of GFRP rebars with $\mathrm{E}_{f}$ of 46,000 MPa except at the plastic hinge areas, where SS rebars are used. GFRP transverse reinforcement is used in both the beams and the columns. The length of the SS rebars is calculated using Eq. (4) that was proposed by Paulay and Priestley [35] and recommended for SS RC elements by Billah and Alam [17]. Perfect bond is assumed between the concrete and the GFRP rebars, as suggested by Barris et al. [13] and Ascione et al. [40]. This 
assumption is valid as long as the GFRP rebars have adequate embedment in the concrete. The GFRP rebars are also anchored to the stainless steel rebars using mechanical couplers, which is expected to prevent any slippage [17].

$$
L_{p}=0.08 \cdot L+0.022 \cdot d_{S S} \cdot f_{y}
$$

where $L$ is half the clear span of the considered beam, $d_{S S}$ is the SS rebar diameter, and $f_{y}$ is the yield strength of the SS rebars.
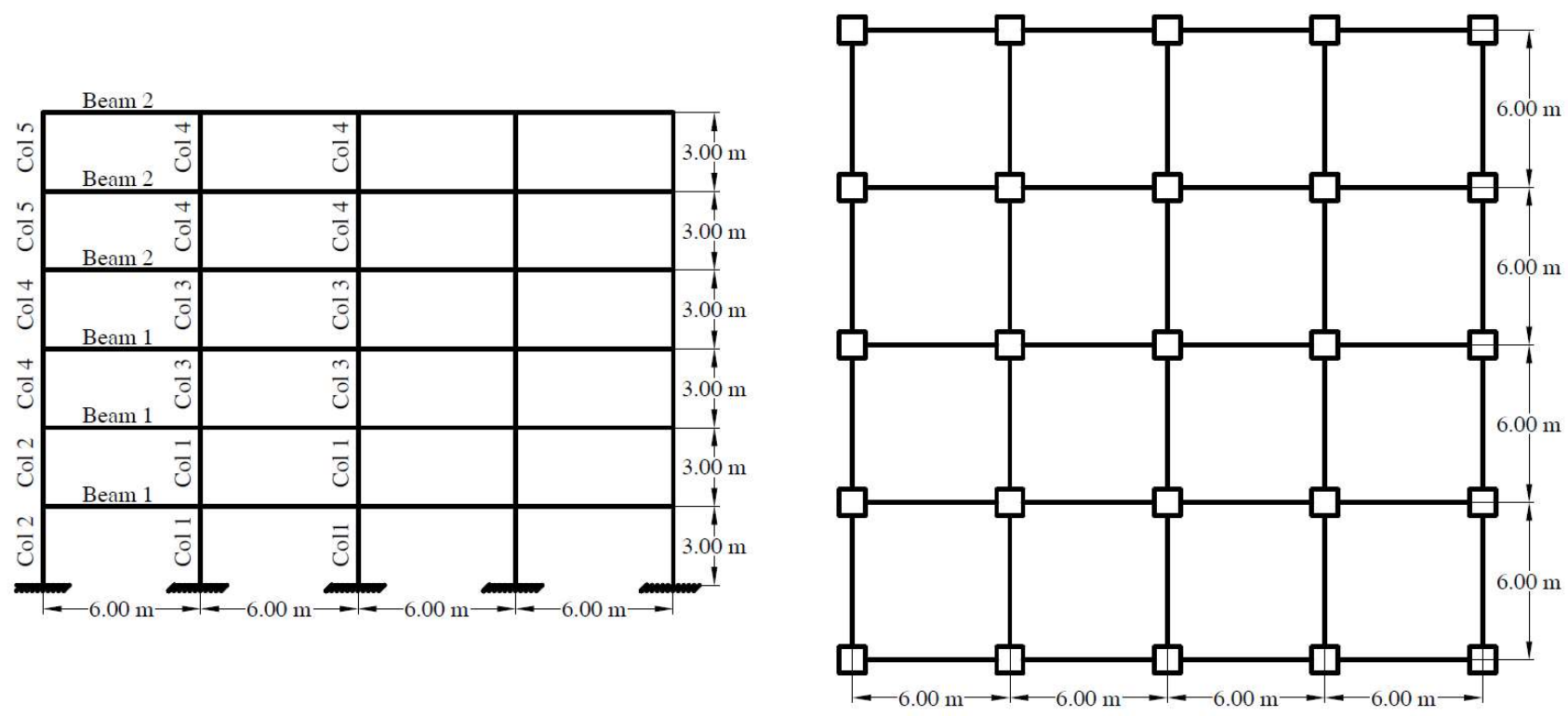

Fig. 2 Elevation and plan views of Frame 1 [39] 

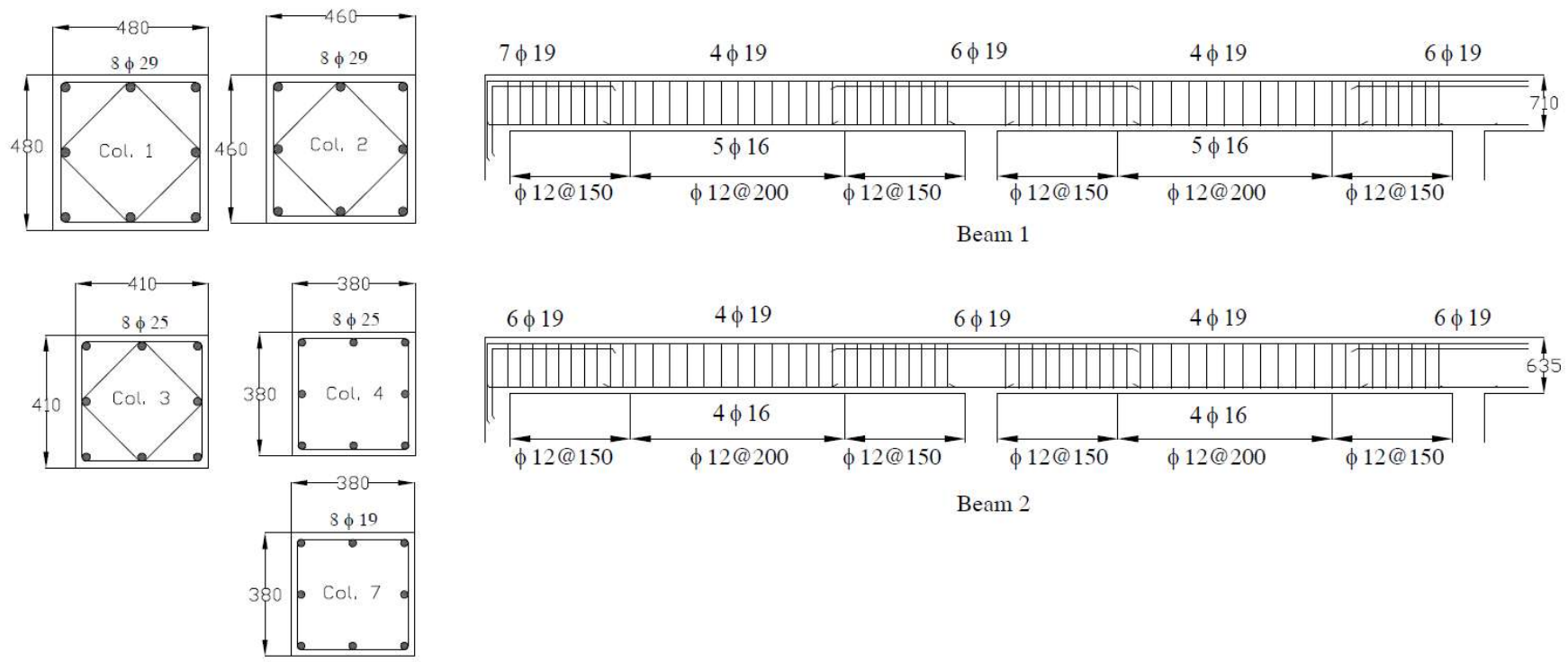

Fig. 3 Cross sections of beams and columns of Frame 1 [39]

The pushover curves for Frames 1 and 2 are shown in Fig. 4. It can be observed that Frame 2, which is expected to be superior in corrosion protection and residual deformations, has lower failure load (-9\%), displacement at failure (-3\%), initial stiffness $(-60 \%)$, and ductility $(-50 \%)$. Such performance is directly related to the modulus of elasticities of the GFRP rebars that is much lower than that of steel rebars. The results emphasize the need for new design criteria for frames reinforced with GFRP and SS rebars. 


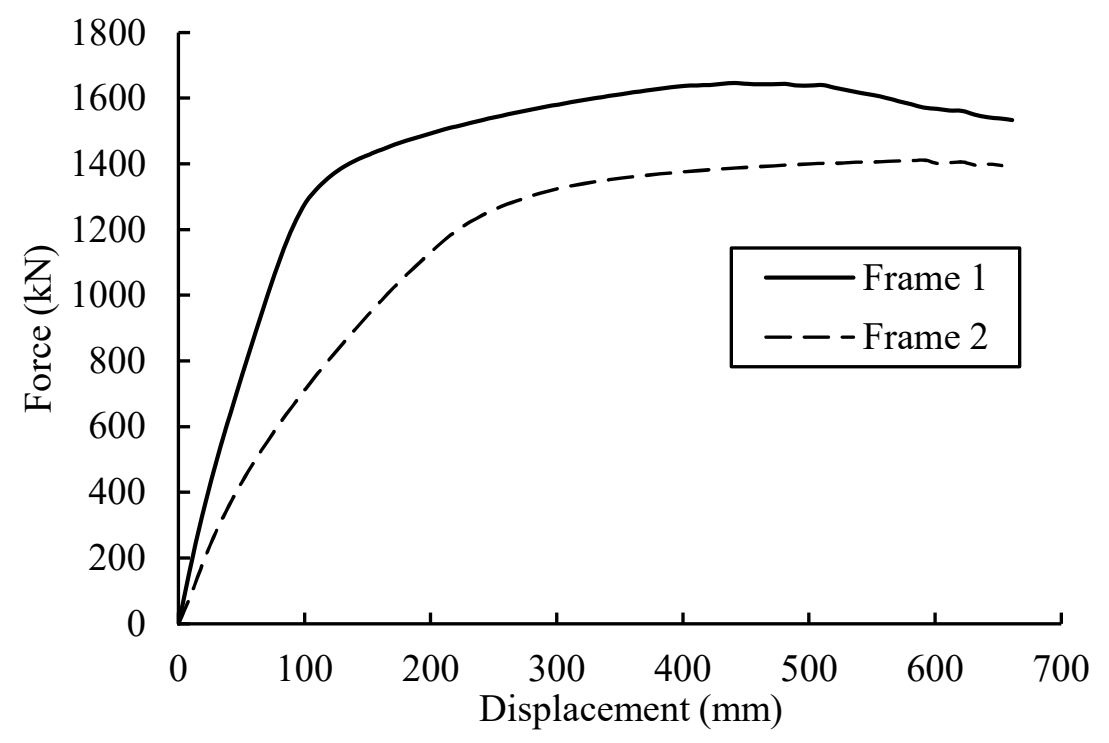

Fig. 4 Pushover curves for Frame 1 and Frame 2.

\section{Design of FRP-SS RC Frames}

A comprehensive parametric study is conducted to understand the lateral performance of RC elements reinforced with combination of SS and GFRP rebars. Results from this study are then utilized to form a design method for such elements.

\subsection{Parametric Study}

The parameters for the analyzed beams are: width $\left(b_{b}=250\right.$ or $\left.400 \mathrm{~mm}\right)$, height $\left(h_{b}=400,600\right.$, or $800 \mathrm{~mm})$, length $(\mathrm{L}=5.0$ or $7.0 \mathrm{~m})$, area of tension rebars $\left(\mathrm{A}_{\mathrm{s}}=\right.$ minimum reinforcing area $\mathrm{A}_{\mathrm{smin}}$, half of the maximum allowable area $1 / 2 \mathrm{~A}_{\mathrm{sb}}$, or maximum allowable area $\mathrm{A}_{\mathrm{sb}}$ ), area of compression

steel rebars $\left(\mathrm{A}_{\mathrm{s}}{ }^{\prime}=0 \%\right.$ or $\left.20 \% \mathrm{~A}_{s}\right)$, and length of the $\mathrm{SS}$ rebars $\left(\mathrm{L}_{s s}=L_{p}\right.$ or $\left.\frac{1}{2} L_{p}\right)$. The reinforcement ratio at the tension side $(\rho)$ is defined as $\rho=\frac{\text { As }}{b_{b} h_{b}}$.

The parameters for the analyzed columns are: width $\left(b_{b}=250\right.$ or $\left.400 \mathrm{~mm}\right)$, section height $\left(\mathrm{h}_{b}=400\right.$, 600 , or $800 \mathrm{~mm}$ ), and column height $(3.0 \mathrm{~m})$.Only GFRP rebars are used in the columns as capacity 
design requires plastic hinges to form in the beams. Three levels of compressive axial load $(10 \%$, $40 \%$, and $70 \%$ of the column axial load capacity) are considered. The reinforcement ratio is varied from $1 \%$ to $4 \%$ with an increment of $1 \%$. The number of longitudinal rebars and the arrangement of the stirrups are selected similar to those of the steel reinforced columns.

The analysis for each of the considered cases of the GFRP-SS RC elements (576 beams and 288 columns) is conducted by applying the axial load, $\mathrm{P}_{\mathrm{A}}$, followed by an incremental lateral load, $\mathrm{P}_{\mathrm{L}}$. The lateral performance is then compared to that of an element reinforced with steel rebars (Steel $\mathrm{RC}$ element) in terms of the overall performance, ductility, initial stiffness, and capacity. The expected lateral performance of a steel RC element and the corresponding GFRP-SS element are shown in Fig. 5. The areas formed between the two curves, $A_{1}^{c}$ and $A_{2}^{c}$, are calculated. If the difference between the two areas is less than 5\%, the overall performance is judged as acceptable. The ductility, initial stiffness and capacity are also compared and a difference less than $10 \%$ is considered acceptable.

If the lateral performance of the GFRP-SS element is judged unacceptable, its design is revised by changing the section height by a factor $F_{h}$ and/or the area of the reinforcing rebars by a factor $F_{r}$. Values of 0.5 to 2.0 with an increment of 0.05 are examined for each factor until a section with almost the same lateral performance as the steel RC section is identified. SeismoStruct batch facility [34] is used to conduct the required iterations. For the GFRP-SS RC elements, it was found that shear failure is not a concern and that the design is governed by flexure. 


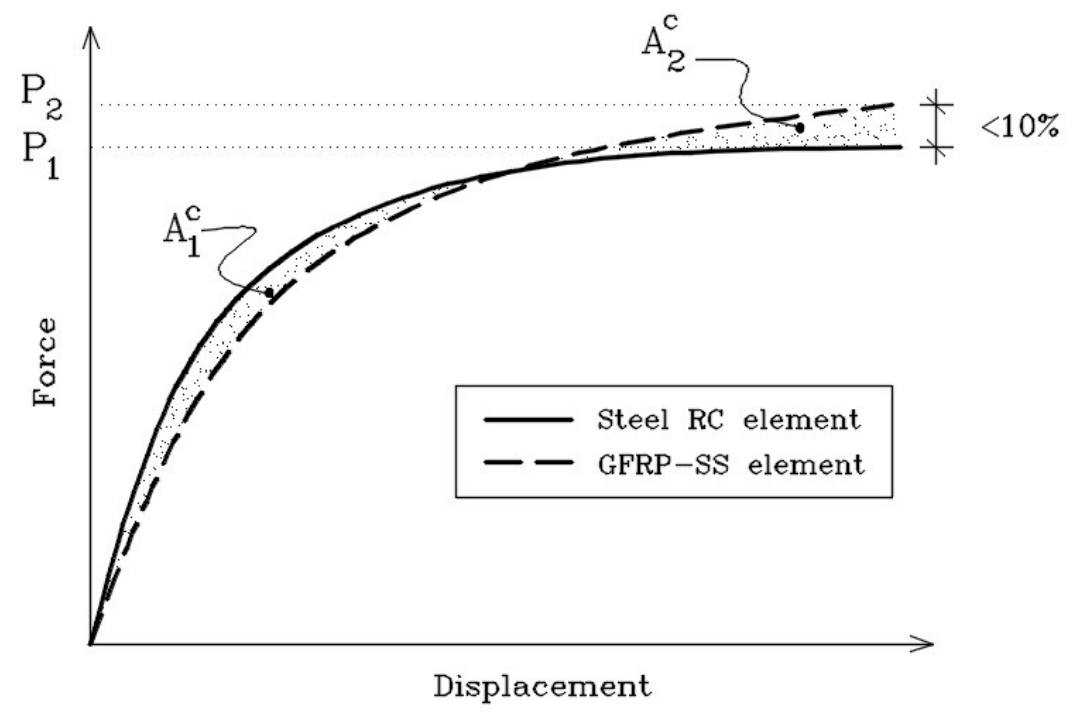

Fig. 5 Expected pushover curves of Steel RC element and GFRP-SS element.

The modifying factors for the beams are found to be affected by the compressive $\left(\rho^{\prime}\right)$ and tension ( $\rho$ ) reinforcement ratios, properties of the GFRP rebars, as well as the length of SS rebars (Lss). On the other hand, the modifying factors for the columns are affected by the level of the axial compressive load $(\mathrm{P})$, reinforcement ratio $(\rho)$ as well as the modulus of elasticity of GFRP $\left(\mathrm{E}_{f}\right)$. Variation of the beam modifying factors is shown in Figs. 6 and 7 for $\mathrm{E}_{f}$ of 46,000 MPa and 65,000 MPa, respectively. The factors in Fig. 7 are lower than those in Fig. 6 because of the higher $\mathrm{E}_{f}$. The height factor $\left(F_{h}\right)$ is always greater than 1 to adjust the element stiffness and it decreases with the increase of either $\rho$ or $\rho^{\prime}$.The reinforcement factor $\left(F_{r}\right)$ reduces the area of the rebars to maintain the load capacity at approximately the same level. The ductility is provided by the SS rebars. For $\mathrm{E}_{f}$ of $46,000 \mathrm{MPa}, F_{r}$ slightly increased with the increase of $\rho$ such that it varied from 0.65 to 0.69 for values of $\rho$ varying between $0.27 \%$ and $4.22 \%$. However, for $\mathrm{E}_{f}$ of $65,000 \mathrm{MPa}, F_{r}$ was found to be a constant value of 0.69 for all values of $\rho$ and $\rho^{\prime}$. 


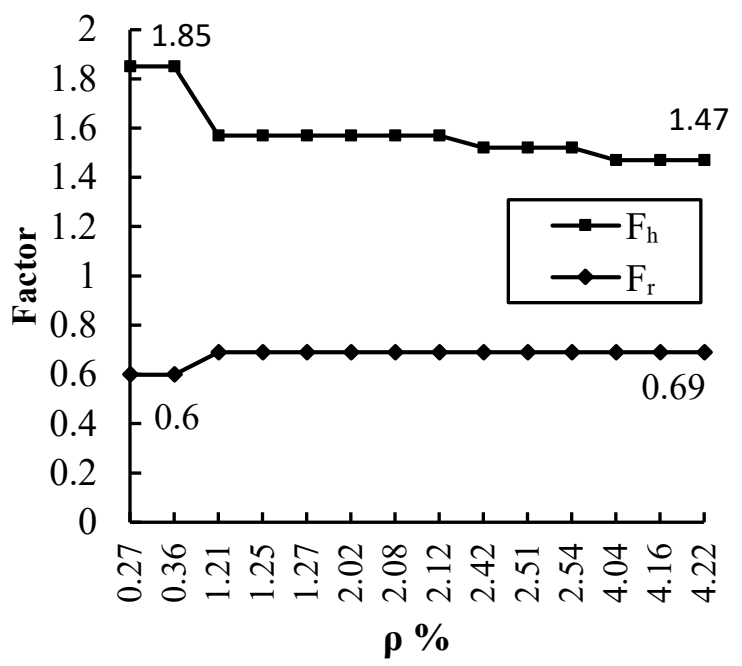

(a) $\rho^{\prime}=0, \mathrm{~L}_{\mathrm{SS}}=\mathrm{L}_{\mathrm{p}}$

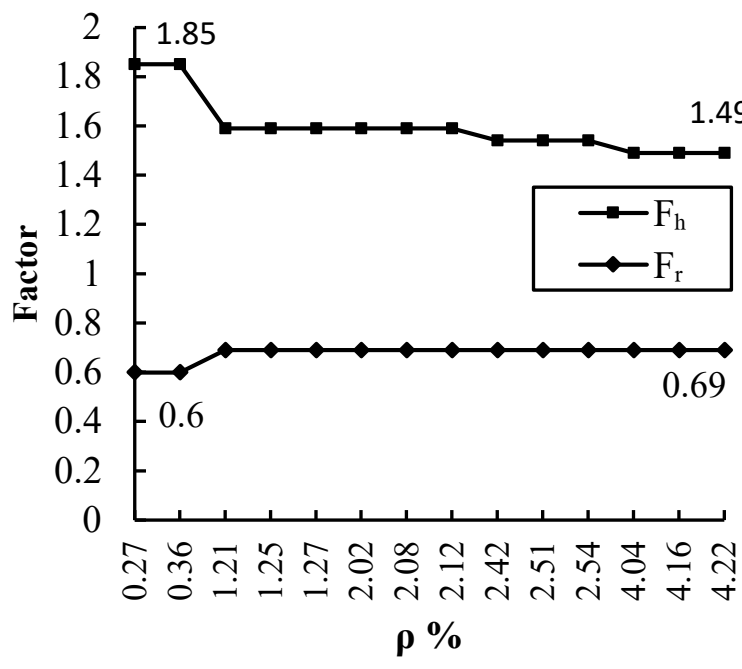

(c) $\rho^{\prime}=0.2 \rho, \mathrm{LSS}_{\mathrm{SS}}=\mathrm{L}_{\mathrm{p}}$

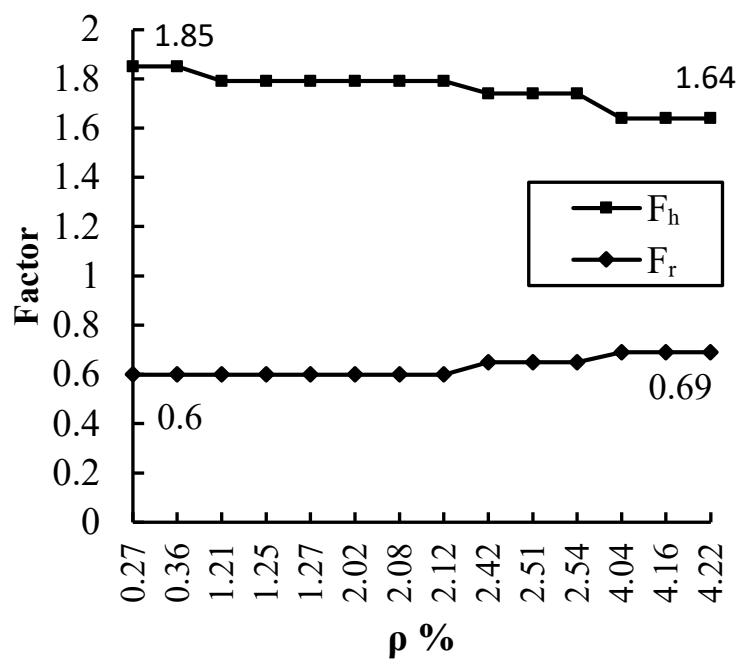

(b) $\rho^{\prime}=0, \mathrm{~L}_{\mathrm{SS}}=1 / 2 \mathrm{~L}_{\mathrm{p}}$

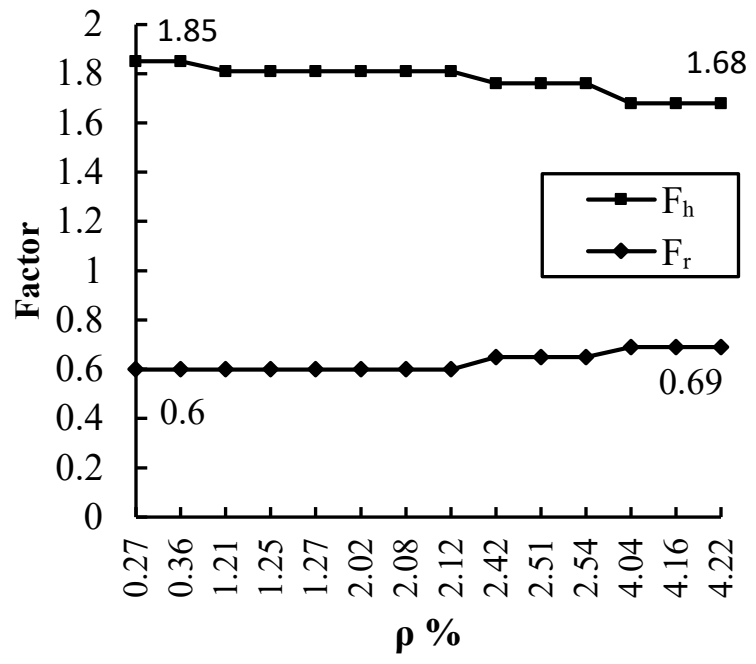

(d) $\rho^{\prime}=0.2 \rho, \mathrm{L}_{\mathrm{SS}}=1 / 2 \mathrm{~L}_{\mathrm{p}}$

Fig. 6 Modifying factors for GFRP-SS RC beams with $\mathrm{E}_{f}=46,000 \mathrm{MPa}$ 


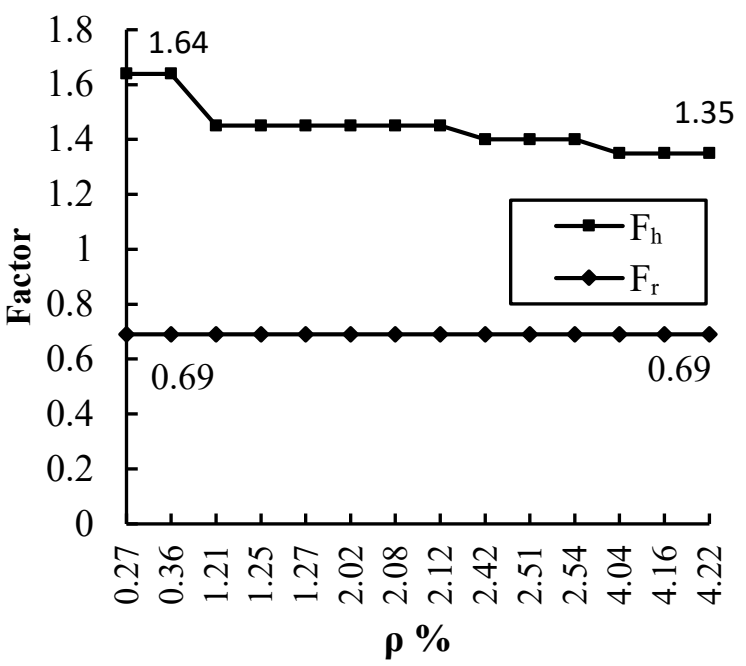

(a) $\rho^{\prime}=0, \mathrm{~L}_{\mathrm{SS}}=\mathrm{L}_{\mathrm{p}}$

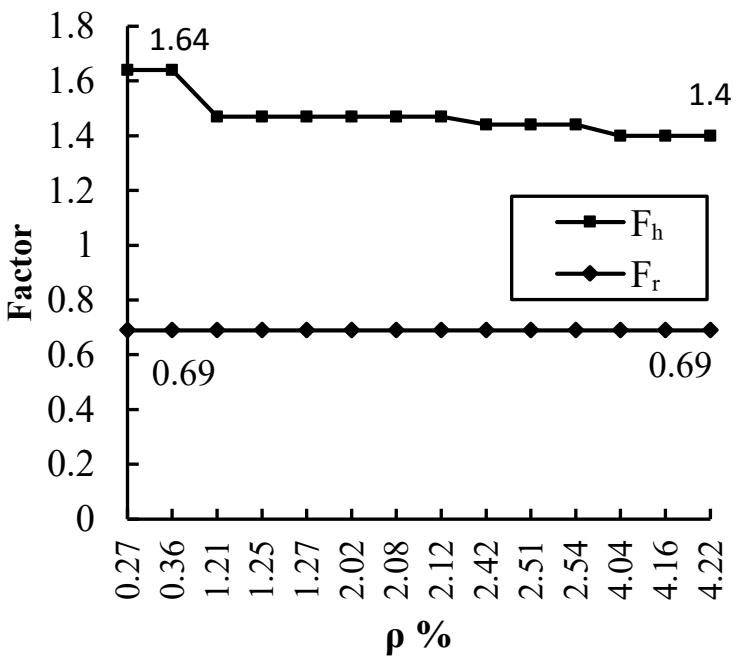

(c) $\rho^{\prime}=0.2 \rho, \mathrm{L}_{S S}=\mathrm{L}_{\mathrm{p}}$

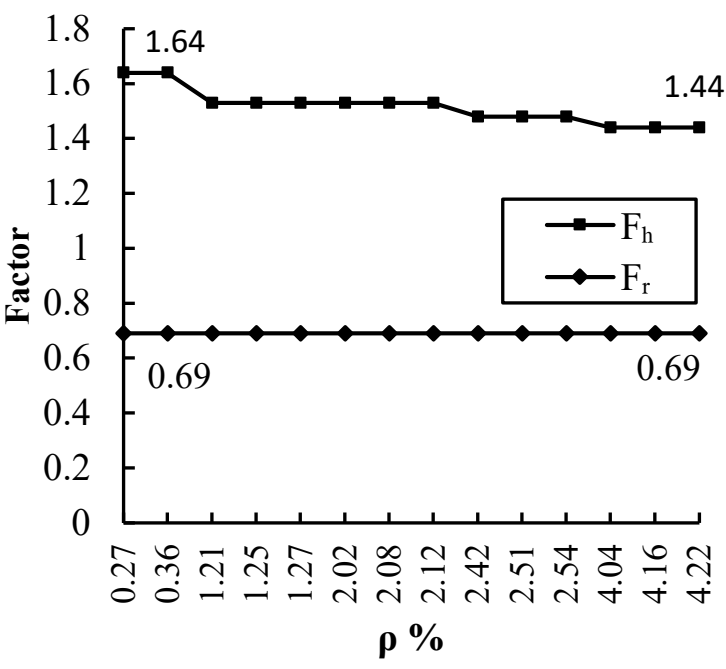

(b) $\rho^{\prime}=0, L_{S S}=1 / 2 L_{p}$

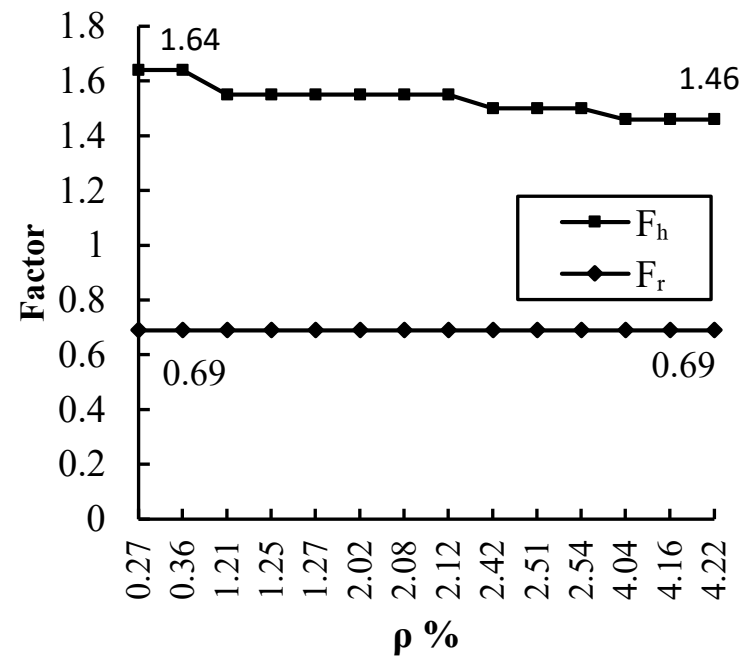

(d) $\rho^{\prime}=0.2 \rho, L_{S S}=1 / 2 L_{p}$

Fig. 7 Modifying factors for GFRP-SS RC beams with $\mathrm{E}_{f}=65,000 \mathrm{MPa}$.

The modifying factors for the columns are shown in Figs. 8 and 9 for $\mathrm{E}_{f}=46,000 \mathrm{MPa}$ and 65,000 $\mathrm{MPa}$, respectively. For $\mathrm{E}_{f}=46,000 \mathrm{MPa}$ and $\rho$ values of $1 \%$ to $4 \%, F_{r}$ varies from 0.84 to 0.90 and $F_{h}$ varied from 1.10 to 1.32 . There is a slight decrease in the height factor with the increase of 
the column's compressive axial force. For $\mathrm{E}_{f}=65,000 \mathrm{MPa}$ and $\rho$ values of $1 \%$ to $4 \%, F_{r}$ varies from 0.84 to 1.00 and $F_{h}$ varies from 1.06 to 1.10 .

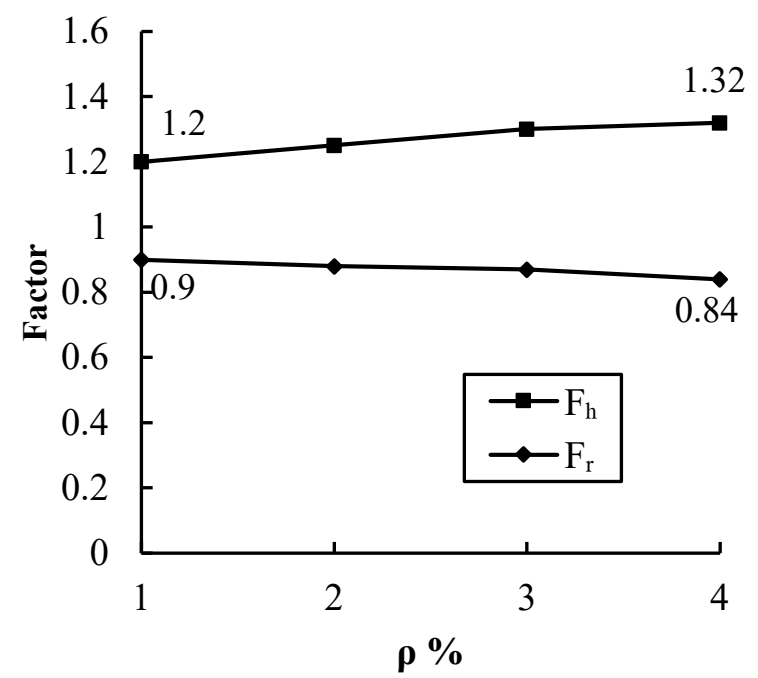

(a) $\mathrm{P}=0.1 \mathrm{P}_{\max }$

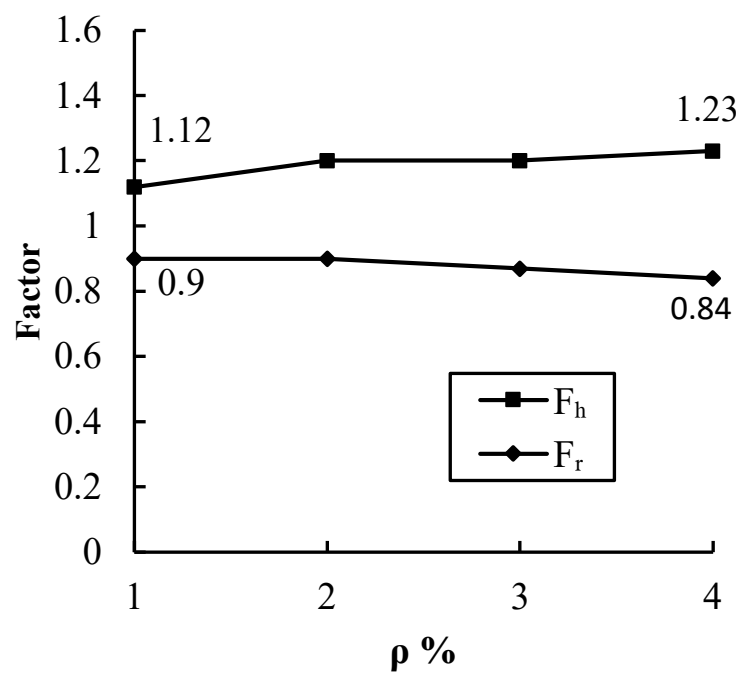

(b) $\mathrm{P}=0.4 \mathrm{P}_{\max }$

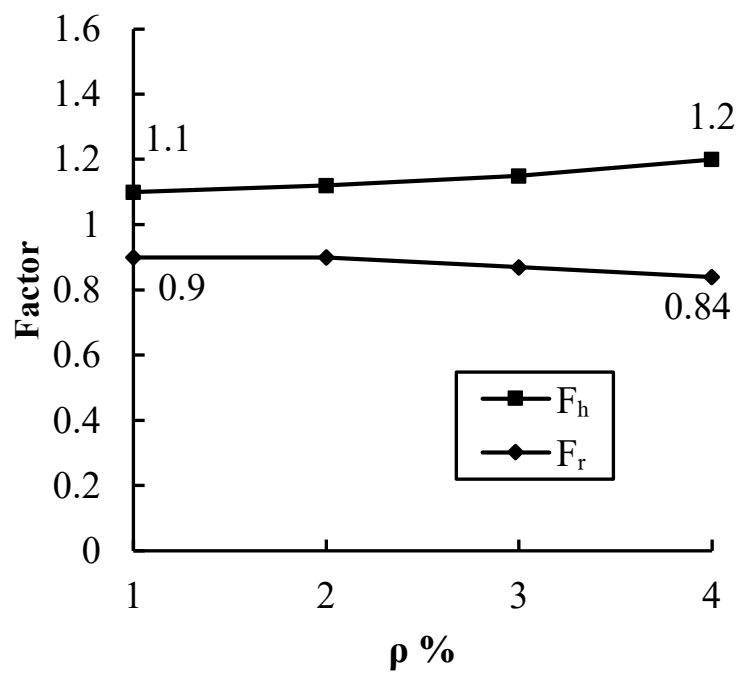

(c) $\mathrm{P}=0.7 \mathrm{P}_{\max }$

Fig. 8 Modifying factors for GFRP RC columns with $\mathrm{E}_{f}=46,000$ MPa. 


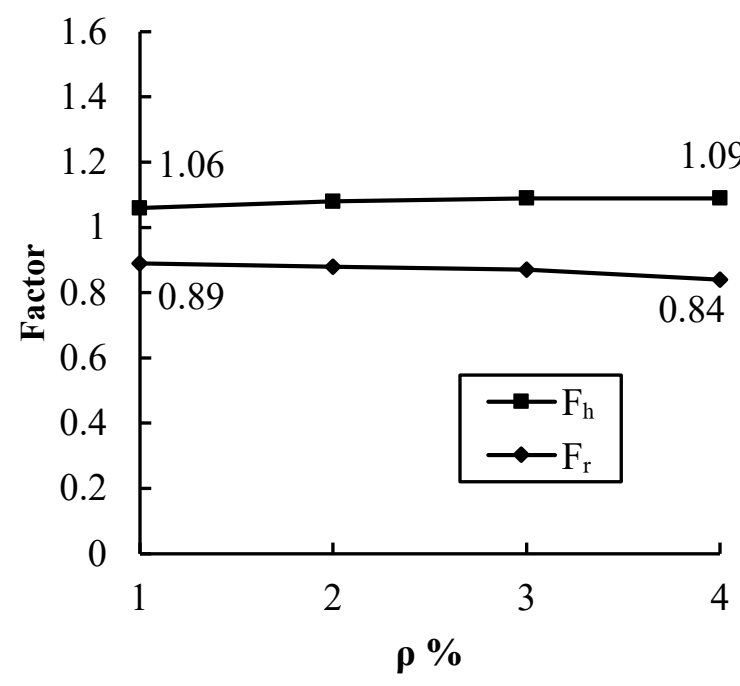

(a) $\mathrm{P}=0.1 \mathrm{P}_{\max }$

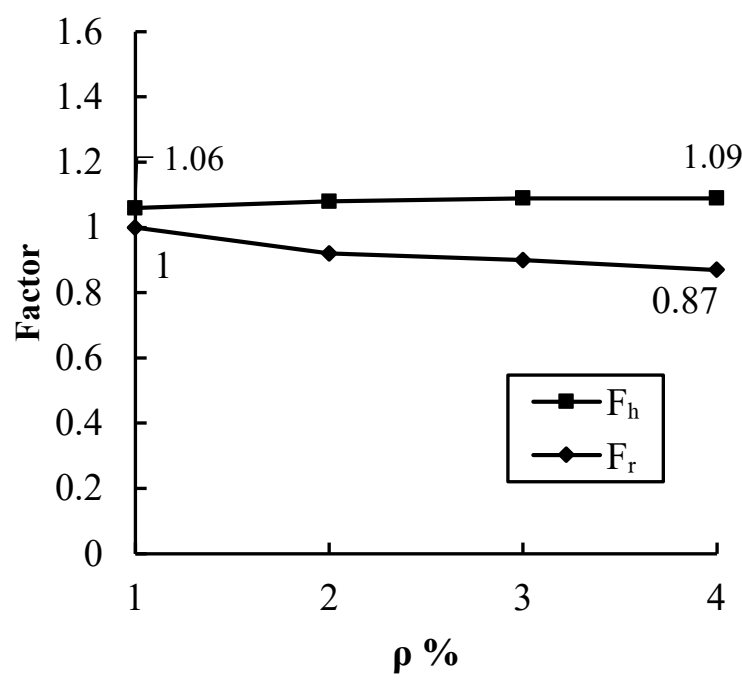

(b) $\mathrm{P}=0.4 \mathrm{P}_{\max }$

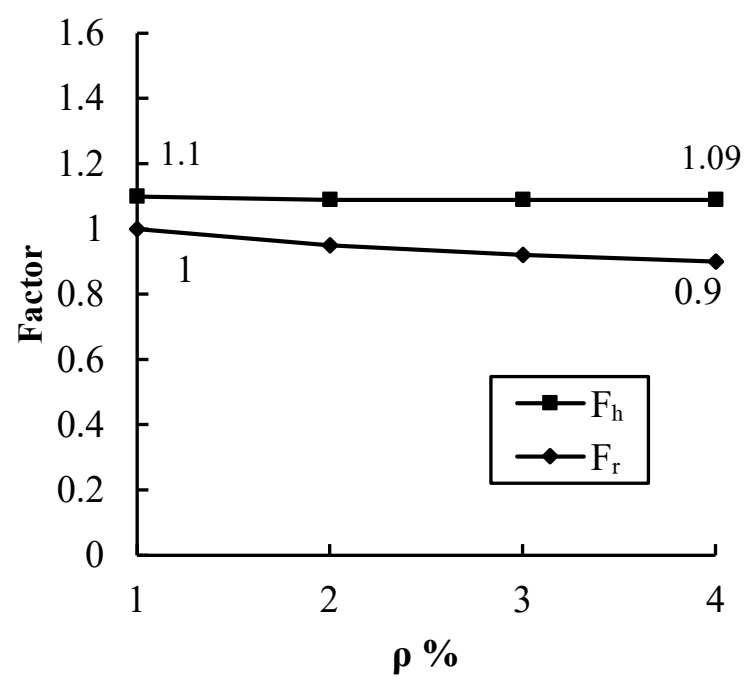

(c) $\mathrm{P}=0.7 \mathrm{P}_{\max }$

Fig. 9 Modifying factors for GFRP RC columns with $\mathrm{E}_{f}=65,000$ MPa.

\subsection{Proposed Design Method}

It is recommended to design the section using steel rebars and then increase the section height and the area of rebars using the factors $F_{h}$ and $F_{r}$. Values for these factors are given by Eqs.(5) and (6) 
for beams reinforced with GFRP and SS rebars. Eqs. (7) and (8) are for columns reinforced with GFRP. These equations were derived using a trial and error procedure. Applying in the equations requires knowledge of the reinforcement ratio, the plastic hinge length, the column axial load, and the GFRP modulus of elasticity.

$$
\begin{aligned}
& F_{h}=\left\{\begin{array}{lc}
1.85\left(\frac{46,000 M P a}{E_{f}}\right)^{0.35} & \rho \leq 0.36 \\
1.58\left(\frac{46,000 M P a}{E_{f}}\right)^{1.55} & 1.21 \leq \rho \leq 2.12 \\
1.53\left(\frac{46,000 M P a}{E_{f}}\right)^{1.55} & 2.42 \leq \rho \leq 2.54 \\
1.48\left(\frac{46,000 M P a}{E_{f}}\right)^{1.58} & 4.04 \leq \rho
\end{array} A T \mathrm{~L}_{\mathrm{SS}}=\mathrm{L}_{\mathrm{P}}\right)(5 a) \\
& F_{h}=\left\{\begin{array}{lc}
1.85\left(\frac{46,000 M P a}{E_{f}}\right)^{0.35} & \rho \leq 0.36 \\
1.80\left(\frac{46,000 M P a}{E_{f}}\right)^{1.32} & 1.21 \leq \rho \leq 2.12 \\
1.75\left(\frac{46,000 M P a}{E_{f}}\right)^{1.32} & 2.42 \leq \rho \leq 2.54 \\
1.66\left(\frac{46,000 M P a}{E_{f}}\right)^{1.40} & 4.04 \leq \rho
\end{array}\right. \\
& F_{r}=\left\{\begin{array}{c}
0.6 \rho \leq 0.36 \\
0.69 \rho \geq 1.21
\end{array} \text { AT } E_{f}=46,000 M P a \text { and }\left(\mathrm{L}_{\mathrm{SS}}=\mathrm{L}_{\mathrm{P}}\right)(6 a)\right. \\
& F_{r}=\left\{\begin{array}{l}
0.6 \quad \rho \leq 2.12 \\
0.652 .54 \leq \rho \leq 2.42 \\
0.69 \quad \rho \geq 4.04
\end{array} \text { AT } E_{f}=46,000 M P a \text { and }\left(\mathrm{L}_{\mathrm{SS}}=\frac{1}{2} \mathrm{~L}_{\mathrm{P}}\right)(6 b)\right. \\
& F_{r}=0.69 \quad A T \quad E_{f}=65,000 \mathrm{MPa}(6 c)
\end{aligned}
$$




$$
\begin{gathered}
F_{h}=0.037 \zeta_{1} \rho+1.1 \eta_{1}(7 \mathrm{a}) \\
\zeta_{1}=\left\{\begin{array}{cc}
+0.27 & E_{f}=65,000 \mathrm{MPa} \text { and } P=0.1 P_{\max } \text { or } 0.4 P_{\max } \\
-0.08 & E_{f}=65,000 \mathrm{MPa} \text { and } P=0.7 P_{\max } \\
+1.0 & \text { Otherwise }
\end{array}\right. \\
\eta_{1}=0.95 \quad E_{f}=65,000 \mathrm{MPa} \text { and } P=0.1 P_{\max } \text { or } 0.4 P_{\max }(7 \mathrm{c})
\end{gathered}
$$

\section{Case Study}

The six-storey RC frame (Frame 1) is considered to further examine the developed design method. Frames 2 and 3 are assumed to have the same section dimensions as Frame 1. The reinforcing rebars are replaced with similar areas of GFRP or SS rebars in Frames 2 and 3. $\mathrm{E}_{f}$ is assumed 46,000 MPa for Frame 2 and 65,000 MPa for Frame 3.

The design of Frames 4 and 5 follows the developed method which is presented in section 4.2. The value of $\rho$ at the plastic hinge region for Beams 1 and 2, Fig.2, is $0.77 \%$. The $\rho$ values at other regions of Beams 1 and 2 are $0.44 \%$ and $0.52 \%$, respectively. For the columns, the values of $\rho$ are $2.3 \%, 2.5 \%, 2.33 \%, 2.7 \%$, and $1.6 \%$ for $\mathrm{Col} 1, \mathrm{Col} 2, \mathrm{Col} 3, \mathrm{Col} 4$, and $\mathrm{Col} 5$, respectively. The exterior column axial forces are $34 \%, 27 \%, 29 \%, 21 \%, 16 \%$, and $12 \%$ of the axial load capacities

of the columns in the $1^{\text {st }}, 2^{\text {nd }}, 3^{\text {rd }}, 4^{\text {th }}, 5^{\text {th }}$, and $6^{\text {th }}$ storey, respectively. The axial load ratios for the interior columns are $30 \%, 24 \%, 26 \%, 20 \%, 14 \%$, and $9 \%$.The section height and the area of the 
reinforcing rebars are adjusted using the developed method. The modifying factors, obtained from the developed method for Frames 4 and 5, are presented in Table 3. The pushover curves for the five frames are shown in Fig. 10. The differences between the initial stiffness, failure load, strength, and ductility of Frame 1, Frame 2, and Frame 3 are quite significant. On the other hand, Frames 4 and 5 lateral performance is very similar to that of Frame 1. For the steel and GFRP-SS $\mathrm{RC}$ frames, it was found that shear failure is not a concern and that the design is governed by flexure. The difference between the vertical displacements at failure of the three frames did not exceed $10 \%$.

Table 3 Modifying factors for Frames 4 and 5

\begin{tabular}{|c|c|c|c|c|}
\hline & \multicolumn{2}{|c|}{ Frame 4 } & \multicolumn{2}{c|}{ Frame 5 } \\
\hline Section & $F_{h}$ & $F_{r}$ & $F_{h}$ & $F_{r}$ \\
\hline Beam 1 $^{\mathrm{P}}$ & 1.72 & 0.64 & 1.29 & 0.69 \\
\hline Beam 2 $^{\mathrm{P}}$ & 1.72 & 0.64 & 1.29 & 0.69 \\
\hline Beam 1 $^{\mathrm{O}}$ & 1.82 & 0.61 & 1.57 & 0.69 \\
\hline Beam 2 $^{\mathrm{O}}$ & 1.80 & 0.62 & 1.50 & 0.69 \\
\hline Col 1 & 1.19 & 0.89 & 1.12 & 0.93 \\
\hline Col 2 & 1.19 & 0.88 & 1.12 & 0.92 \\
\hline Col 3 & 1.19 & 0.88 & 1.12 & 0.93 \\
\hline Col 4 & 1.20 & 0.87 & 1.12 & 0.93 \\
\hline Col 5 & 1.20 & 0.87 & 1.12 & 0.90 \\
\hline
\end{tabular}

${ }^{\mathrm{P}}$ At the plastic hinge region ${ }^{\mathrm{O}}$ Outside the plastic hinge region 


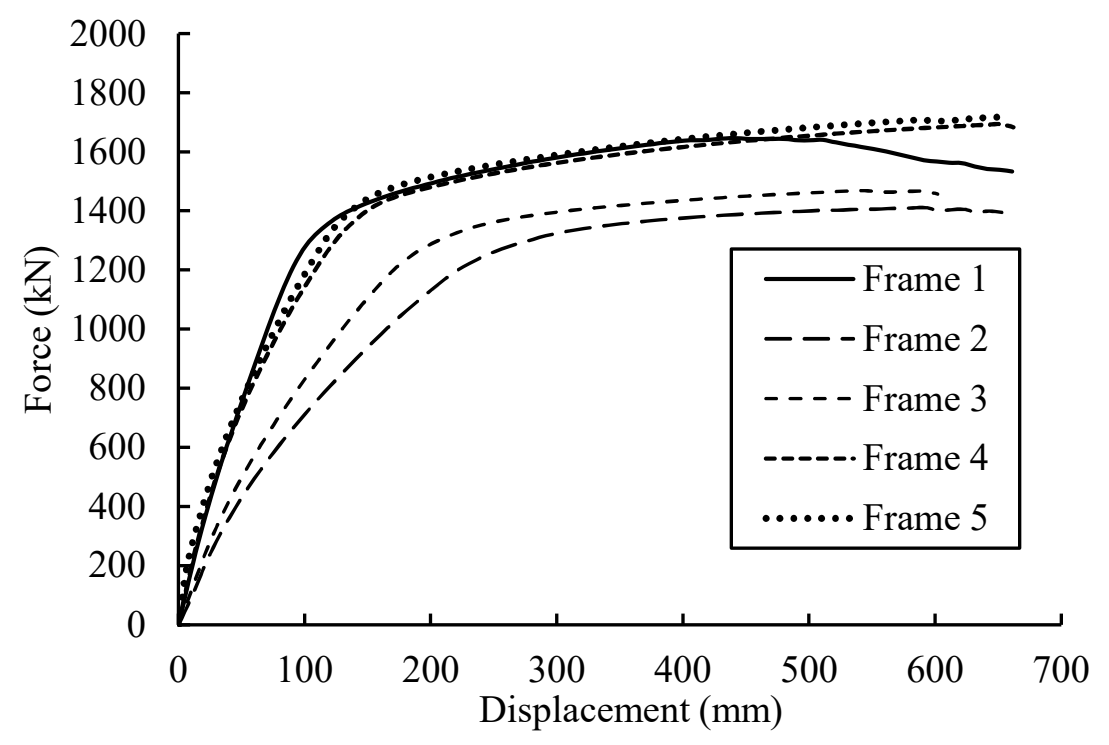

Fig. 10 Lateral performance of Frames 1 to 5.

\section{Conclusions}

In this paper, the concept of hybrid GFRP and SS rebars is adopted to have a corrosion free RC frame that possesses adequate ductility, strength, and stiffness. The SS rebars are used as reinforcement at the plastic hinge regions to provide the system with adequate ductility and energy dissipation. Suitable couplers are assumed to link the FRP and SS rebars. The objectives of this study are: (1) assessing the performance of concrete elements reinforced with SS rebars at the plastic hinge regions and GFRP rebars at the other regions, and (2) developing design criteria to ensure that the GFRP-SS frame lateral performance is acceptable in terms of stiffness, strength, and ductility.

A six-storey steel RC frame (Frame 1) is considered. Frames 2 and 3 are revised designs of Frame 1, which utilize SS and GFRP instead of steel rebars. The pushover curves for the three frames show that Frames 2 and 3, which are expected to be superior in corrosion protection and residual 
deformations, have lower failure load, displacement at failure, initial stiffness, and ductility when compared to Frame 1.

A comprehensive parametric study is then conducted to form a design method for such elements.

576 beams and 288 columns are considered in this study. Two modification factors for the section height and area of steel are proposed. Values for these factors can be estimated using the equations $(5),(6),(7)$, and (8). The developed factors are used to modify the design of Frames 2 and 3 and they have led to a lateral performance that is comparable to the steel RC frame.

Conclusions of this study are limited to the examined cases. Future analytical and experimental studies investigating elements critical in shear and elements having GFRP rebars with slippage problems are needed.

\section{References}

1. Said, A. M., and M. L. Nehdi. "Use of FRP for RC Frames in Seismic Zones: Part I. Evaluation of FRP Beam-Column Joint Rehabilitation Techniques.” Applied Composite Materials 11, no. 4 (2004): 205-26.

2. Nehdi, M., and A. Said. "Performance of RC Frames with Hybrid Reinforcement under Reversed Cyclic Loading.” Materials and Structures 38, no. 6 (2005): 627-37.

3. Razzaq Z., Mojtaba S. and Prabhakaran R. "LRFD approach for FRP channel section columns" Journal of Reinforced Plastics and Composites 28, no. 12 (2008):1409-1415.

4. Harris, H.G., Somboonsong, W., Ko, F.K., 1998. New Ductile Hybrid FRP Reinforcing Bar for Concrete Structures. Journal of Composites for Construction 2, 28-37.

5. Benmokrane, B., 0 Chaallal, and R. Masmoudi. "Flexural Response of Concrete Beams Reinforced with FRP Reinforcing Bars.” Structural Journal 93, no. 1 (1996): 46-55. 
6. Alsayed, S. H, Y. A Al-Salloum, and T. H Almusallam. "Performance of Glass Fiber Reinforced Plastic Bars as a Reinforcing Material for Concrete Structures.” Composites Part B: Engineering 31, no. 6-7 (2000): 555-67.

7. Ferreira, A. J. M, P. P Camanho, A. T Marques, and A. A Fernandes. "Modelling of Concrete Beams Reinforced with FRP Re-Bars.” Composite Structures 53, no. 1 (2001): 107-16.

8. Tavares, C. M. L., M. C. S. Ribeiro, A. J. M. Ferreira, and R. M. Guedes. "Creep Behaviour of FRP-Reinforced Polymer Concrete.” Composite Structures 57, no. 1-4 (2002): 47-51.

9. Rasheed, H. A., R. Nayal, and H. Melhem. "Response Prediction of Concrete Beams Reinforced with FRP Bars.” Composite Structures 65, no. 2 (2004): 193-204.

10. Wegian, F. M., and H. A. Abdalla. "Shear Capacity of Concrete Beams Reinforced with Fiber Reinforced Polymers." Composite Structures 71, no. 1 (2005): 130-38.

11. Li, G., D. Maricherla, K. Singh, S. Pang, and M. John. "Effect of Fiber Orientation on the Structural Behavior of FRP Wrapped Concrete Cylinders.” Composite Structures 74, no. 4 (2006): 475-83.

12. Rougier, V. C., and B. M. Luccioni. "Numerical Assessment of FRP Retrofitting Systems for Reinforced Concrete Elements.” Engineering Structures 29, no. 8 (2007): 1664-75.

13. Barris, C., Ll. Torres, A. Turon, M. Baena, and A. Catalan. "An Experimental Study of the Flexural Behaviour of GFRP RC Beams and Comparison with Prediction Models.” Composite Structures 91, no. 3 (2009): 286-95.

14. Lau, D., and H. Pam. "Experimental Study of Hybrid FRP Reinforced Concrete Beams." Engineering Structures 32, no. 12 (2010): 3857-65. 
15. Al-Sunna, R., K. Pilakoutas, I. Hajirasouliha, and M. Guadagnini. "Deflection Behaviour of FRP Reinforced Concrete Beams and Slabs: An Experimental Investigation.” Composites Part B: Engineering 43, no. 5 (2012): 2125-34.

16. Kara, I., and A. Ashour. "Flexural Performance of FRP Reinforced Concrete Beams." Composite Structures 94, no. 5 (2012): 1616-25.

17. Billah, A.H., Alam, M., 2012. Seismic performance of concrete columns reinforced with hybrid shape memory alloy (SMA) and fiber reinforced polymer (FRP) bars. Construction and Building Materials 28, 730-742.

18. Mias, C., L1 Torres, A. Turon, and I. A. Sharaky. "Effect of Material Properties on Long-Term Deflections of GFRP Reinforced Concrete Beams." Construction and Building Materials 41 (2013): 99-108.

19. Prachasaree, W., Piriyakootorn, S., Sangsrijun, A., Limkatanyu, S., 2015. Behavior and Performance of GFRP Reinforced Concrete Columns with Various Types of Stirrups. International Journal of Polymer Science 2015, 1-9.

20. Tobbi, H., Farghaly, A.S., Benmokrane, B., 2014a. Behavior of Concentrically Loaded FiberReinforced Polymer Reinforced Concrete Columns with Varying Reinforcement Types and Ratios. SJ 111, 375-386.

21. Tobbi, H., A. Farghaly, and B. Benmokrane. 2012. "Concrete Columns Reinforced Longitudinally and Transversally with Glass Fiber-Reinforced Polymer Bars.” ACI Structural Journal109 (4): 551-58.

22. Tobbi, H., A. Farghaly, and B. Benmokrane. 2014b. "Strength Model for Concrete Columns Reinforced with Fiber-Reinforced Polymer Bars and Ties.” ACI Structural Journal 111 (4): 789-98. 
23. Pantelides, C.P., Gibbons, M.E., Reaveley, L.D., 2013. Axial Load Behavior of Concrete Columns Confined with GFRP Spirals. Journal of Composites for Construction 17, 305-313.

24. Mohamed, H.M., Afifi, M.Z., Benmokrane, B., 2014. Performance evaluation of concrete columns reinforced longitudinally with FRP bars and confined with FRP hoops and spirals under axial load. Journal of Bridge Engineering 19, 4014020-12.

25. Afifi, M.Z., Mohamed, H.M., Benmokrane, B., 2014. Axial Capacity of Circular Concrete Columns Reinforced with GFRP Bars and Spirals. Journal of Composites for Construction $18,4013017$.

26. Afifi, M. Z., H. M. Mohamed, and B. Benmokrane., 2015. "Theoretical Stress-strain Model for Circular Concrete Columns Confined by GFRP Spirals and Hoops.” Engineering Structures 102: 202-13.

27 Markeset, G., Rostam, S.and Klinghoffer, O., 2006. "Guide for the use of stainless steel reinforcement in concrete structures." Nordic Innovation Centre project - 04118: «Corrosion resistant steel reinforcement in concrete structures (NonCor) ».

28. García-Alonso, M. C., Escudero, M. L., Miranda, M. L., Vega, M. I., Capilla, F. Correia, M. J., Salta, M. Bennani, A. and González, J. A.2007. “Corrosion Behaviour of New Stainless Steels Reinforcing Bars Embedded in Concrete." Cement and Concrete Research 37(10): $1463-71$.

29. Baddoo, N. R. 2008. "Stainless Steel in Construction: A Review of Research, Applications, Challenges and Opportunities." Journal of Constructional Steel Research, International Stainless Steel Experts Seminar 64(11): 1199-1206. 
30. Elsener, B., Addari, D., Coray, S. and Rossi, A. 2011. "Stainless Steel Reinforcing Bars Reason for Their High Pitting Corrosion Resistance.” Materials and Corrosion 62(2): 11119.

31. Alam, M., M. Nehdi, and M. Youssef., 2009. "Seismic Performance of Concrete Frame Structures Reinforced with Superelastic Shape Memory Alloys.” Smart Structures and Systems 5 (5): 565-85.

32. Mander, J., Priestley, M. and Park, R., 1988. "Theoretical Stress-Strain Model for Confined Concrete." Journal of Structural Engineering 114 (8): 1804-26.

33. Martinez-Rueda, J. E., and Elnashai, A. S. 1997. "Confined Concrete Model under Cyclic Load." Materials and Structures 30 (3): 139-47.

34. SeismoSoft 2009 "SeismoStruct- A computer program for static and dynamic nonlinear analysis of framed structures", Available from URL: http://www.seismosoft.com/SeismoStruct/index.htm.

35. Paulay T. and Priestley M.J.N., 1992 “Seismic Design of Reinforced Concrete and Masonry Buildings", John Wiley \& Sons, New York.

36. Priestley, M.J.N., and J.H Wood. 1977. "Behaviour of a Complex Prototype Box Girder Bridge." In Proceedings of the RILEM International Symposium on Testing In-Situ of Concrete Structures, 1:140-53. Budapest.

37. American concrete institute, ACI committee 318, 2014. ACI 318-14, Building Code Requirement for Structure Concrete.

38. Bentz, E.C., Massam, L., Collins, M.P. Shear strength of large concrete members with FRP reinforcement (2010) Journal of Composites for Construction, 14 (6), pp. 637-646. 
39. Youssef, M.A., and Elfeki, M.A. 2012. "Seismic Performance of Concrete Frames Reinforced with Superelastic Shape Memory Alloys.” Smart Structures and Systems 9 (4): 313-33.

40. Ascione, L., Mancusi, G., Spadea, S., 2010, Flexural behaviour of concrete beams reinforced with GFRP bars. Strain, 46 (5), pp. 460-469. 